\title{
Cultivation of Chlamydia trachomatis in Cycloheximide- Treated McCoy Cells
}

\author{
K. TORVALD RIPA* AND PER-ANDERS MÅRDH \\ Institute of Medical Microbiology, University of Lund, S-223 62 Lund, Sweden
}

Received for publication 23 May 1977

\begin{abstract}
An isolation technique for Chlamydia trachomatis using McCoy cells is described. In contrast to earlier techniques employing such cells, no pretreatment of the cells was used. The glutarimide antibiotic cycloheximide was added to the culture medium used for incubating the cells after infection. Cycloheximide was used at concentrations that depressed, but did not completely inhibit, the metabolism of the eucaryotic host cells. In studies on different immunotypes of $C$. trachomatis cultured in the yolk sac of embryonated hen eggs, the cycloheximide technique was compared with a method using pretreatment of cells with 5-iodo2-deoxyuridine. The cycloheximide method gave greater numbers of inclusionforming units per cover slip for all the immunotypes of trachoma-inclusion conjunctivitis agents tested, i.e., A through I. In a study of 194 cervical and urethral specimens from women, cycloheximide treatment of McCoy cells was found to be more efficient than 5-iodo-2-deoxyuridine treatment for the isolation of $C$. trachomatis.
\end{abstract}

In 1957 T'ang et al. succeeded in growing Chlamydia trachomatis in the yolk sac of embryonated hen eggs (17). In the early 1960 s, Gordon and co-workers were able to grow the organism in cell cultures (6), and in 1965 they reported on the isolation of $C$. trachomatis from the eye of a patient with trachoma by using irradiated McCoy cells (7). This technique, although now slightly modified, is still one of the most commonly used methods for the isolation of Chlamydia. The use of irradiated McCoy cells is laborious, however, and the development of more easily performed techniques would be desirable. Examples of other culture methods are those involving the use of diethylaminoethyl-dextran-treated HeLa 229 cells (11) and McCoy cells pretreated with 5-iodo-2-deoxyuridine (IUdR) (20) or cytochalasin B (16). All of these techniques have been shown to be as efficient as the use of irradiated McCoy cells for the isolation of Chlamydia from clinical specimens.

Cycloheximide is a glutarimide antibiotic (15) which inhibits the deoxyribonucleic acid and protein synthesis of eucaryotic cells (4) but does not affect procaryotic cells such as Chlamydia $(1,2)$.

The purpose of our study was to develop an isolation technique for $C$. trachomatis that does not require pretreatment of the eucaryotic host cells. A method is described in which cycloheximide is added to the culture medium at the time of infecting the McCoy cell cultures. The results of a comparative study in which cyclo- heximide- and IUdR-treated McCoy cells were used to isolate Chlamydia from urethral and cervical specimens are also presented.

\section{MATERIALS AND METHODS}

Organisms. The following strains of C. trachomatis, supplied by San-Pin Wang, University of Washington, Seattle, were used: A/G-17/OT, B/TW-5/OT, C/TW-3/OT, D/UW-3/Cx, E/UW-5/Cx, F/UW-6/Cx, G/UW-27/Cx, H/UW-43/Cx, I/UW-12/Ur, LGV-I (810), LGV-II (JH), and LGV-III/404/Bubo. The organisms were cultured in the yolk sac of 6- to 8-dayold embryonated hen eggs and harvested 7 to 8 days later. The infected yolk sac material was diluted 1:20 in sucrose-phosphate buffer (2-SP) (5), containing $10 \%$ fetal bovine serum ( $\mathrm{vol} / \mathrm{vol}), 10 \mu \mathrm{g}$ of gentamicin (Schering) per $\mathrm{ml}$, and $2.5 \mu \mathrm{g}$ of amphotericin B (Squibb) per ml. The diluted samples were stored at $-90^{\circ} \mathrm{C}$ until use. Further dilutions to final concentrations of yolk sac material of $1: 1,000$ to $1: 20,000$ necessary to obtain suitable inclusion counts (i.e., 10 to 300 inclusions per cover slip) were made in tissue culture medium (see below) immediately before the cell cultures were infected with chlamydiae.

Cultured cells. The McCoy cells used were originally obtained from S. Darougar, Institute of Ophthalmology, University of London, London.

Cell culture medium. Cells were grown in Earle balanced salt solution containing $5 \%$ fetal bovine serum, $2 \%$ amino acids, $1 \%$ vitamins, $1 \%$ glutamine (all from Flow Laboratories, Irvine, Scotland, U.K.), 0.16\% $\mathrm{NaHCO}_{3}$ (wt/vol), $10 \mu \mathrm{g}$ of gentamicin (Schering) per $\mathrm{ml}$ and $2.5 \mu \mathrm{g}$ of amphotericin B (Squibb) per ml. When the cells were infected with chlamydiae, the same medium with the addition of $0.5 \%$ glucose (wt/vol) was used. 
IUdR (Iduridin, Ferring, Malmö, Sweden; and Stoxil, Smith, Kline \& French Inc., Philadelphia, Pa.) and cycloheximide (Acti-dione, Upjohn) were used for treatment of cell cultures as described below.

Cell culture technique. McCoy cells were cultured in glass flasks for $72 \mathrm{~h}$. The cells were suspended after addition of ethylenediamine tetraacetate (Versene, Merck). One-milliliter volumes of the cell suspension, containing $10^{5}$ cells, were transferred to flat-bottomed plastic tubes containing a cover slip (13 $\mathrm{mm}$ in diameter). The cells were incubated at $37^{\circ} \mathrm{C}$ for $24 \mathrm{~h}$ to obtain a confluent cell layer. IUdR treatment of the McCoy cells was done according to the method of Wentworth and Alexander (20). Stoxil was regularly used, but Iduridin was used in some experiments. Before inoculation, the cell culture medium was aspirated and replaced with $1.0 \mathrm{ml}$ of infected yolk sac material that had been diluted in cell culture medium. When clinical specimens were studied, $0.5 \mathrm{ml}$ of the samples, diluted in $0.5 \mathrm{ml}$ of tissue culture medium, was added to each tube. The inoculum was centrifuged onto the McCoy cells at $3,100 \times g$ at $35^{\circ} \mathrm{C}$ for $60 \mathrm{~min}$ (Wifug Clinic, AB Winkelcentrifug, Stockholm, Sweden). After centrifugation, the tubes were incubated for $2 \mathrm{~h}$ at $37^{\circ} \mathrm{C}$, and thereafter the medium was replaced by $2 \mathrm{ml}$ of fresh cell culture medium, containing $2 \%$ glucose. When cycloheximide was used, it was added to the culture medium at concentrations of 0.5 , $1.0,2.0$, and $4.0 \mu \mathrm{g} / \mathrm{ml}$. The tubes were incubated at $37^{\circ} \mathrm{C}$ for 3 days, and the cells were stained with iodine. The number of inclusion-forming units (IFU) was determined by examining the cells under a light microscope. All comparative tests were carried out concurrently in triplicate for each strain.

Clinical specimens. The same 194 cervical and female urethral specimens were cultured in McCoy cells treated with $2 \mu \mathrm{g}$ of cycloheximide and in cells treated with $25 \mu \mathrm{g}$ of IUdR per $\mathrm{ml}$ of cell culture medium. The specimens were collected with a cottontipped swab from patients with signs of infection in the lower genital tract and also from patients with neither history nor signs of genital infection. Transport medium used was 2-SP containing 5\% fetal bovine serum, $10 \mu \mathrm{g}$ of gentamicin per $\mathrm{ml}$, and $2.5 \mu \mathrm{g}$ of amphotericin B per $\mathrm{ml}$. When not tested on the day of collection, the specimens were stored frozen at $-90^{\circ} \mathrm{C}$.

\section{RESULTS}

IUdR treatment. Treatment of McCoy cells with the IUdR drug Iduridin had no effect on the number of IFU as compared to untreated cells unless at least $800 \mu \mathrm{g} / \mathrm{ml}$ was used. However, at this concentration, the drug had a nonspecific, cytotoxic effect on the McCoy cells. When the IUdR drug Stoxil was used at a concentration of $25 \mu \mathrm{g} / \mathrm{ml}$, an increase in the number of IFU was noted as compared to those in untreated cells for most immunotypes of $C$. trachomatis. This concentration of Stoxil had no cytotoxic effect.

Cycloheximide treatment. Table 1 shows the mean number of inclusions in three cultures of trachoma-inclusion conjunctivitis agents (TRIC) immunotypes A, B, C, D, and E, using different concentrations of cycloheximide. The inclusion counts were calculated from the mean number of IFU per cover slip as the number of IFU per milliliter of infected yolk sac material. When $4 \mu \mathrm{g}$ of cycloheximide per $\mathrm{ml}$ (or higher concentrations) was used, a nonspecific cytotoxic effect was noted; i.e., the cells detached from the cover slip and became granular. The highest IFU count was obtained with $2 \mu \mathrm{g}$ of cycloheximide per $\mathrm{ml}$.

Comparison of the number of IFU obtained in untreated and IUdR- and cycloheximide-treated cells. The number of IFU per milliliter (calculated from the mean number of IFU per cover slip in three cultures) obtained in cultures infected with yolk sac material of various immunotypes of TRIC organisms in untreated and IUdR ( $25 \mu \mathrm{g}$ of Stoxil per ml)- and cycloheximide $(2 \mu \mathrm{g} / \mathrm{ml})$-treated McCoy cells is shown in Table 2. Cycloheximide treatment gave IFU counts 2 to 30 times higher than those obtained with the IUdR-treated cells. The lym-

TABLE 1. Culture of $C$. trachomatis immunotypes $A$, $B, C, D$, and $E$ in McCoy cells treated with various concentrations of cycloheximide

\begin{tabular}{ccccc}
\hline \multirow{2}{*}{ Immunotype } & \multicolumn{4}{c}{ Concn of cycloheximide used $(\mu \mathrm{g} / \mathrm{ml})$} \\
\cline { 2 - 5 } & 0.5 & 1.0 & 2.0 & 4.0 \\
\hline $\mathrm{A}$ & $\mathrm{NT}^{a}$ & $165^{b}$ & 181 & 140 \\
$\mathrm{~B}$ & $\mathrm{NT}$ & 16.0 & 47.4 & 58.0 \\
$\mathrm{C}$ & 15.3 & 56.0 & 62.0 & 61.4 \\
$\mathrm{D}$ & $\mathrm{NT}$ & 510 & 580 & 593 \\
$\mathrm{E}$ & 144 & 314 & 478 & 250 \\
\hline
\end{tabular}

${ }^{a}$ NT, Not tested.

${ }^{b}$ Number of IFU per milliliter $\left(\times 10^{4}\right)$ of infected yolk sac material (each value represents the mean of three cultures).

TABLE 2. Culture of various immunotypes of $C$. trachomatis in untreated and IUdR (Stoxil)- and cycloheximide-treated McCoy cells

\begin{tabular}{cccc}
\hline & \multicolumn{3}{c}{ Treatment of cells } \\
\cline { 2 - 4 } Immunotype & None & $\begin{array}{c}\text { IUdR } \\
(25 \mu \mathrm{g} / \mathrm{ml})\end{array}$ & $\begin{array}{c}\text { Cycloheximide } \\
(2 \mu \mathrm{g} / \mathrm{ml})\end{array}$ \\
\hline & $38.6^{a}$ & 48.0 & 166 \\
A & 15.2 & 9.6 & 85.0 \\
B & 1.3 & 2.0 & 62.0 \\
C & 72.0 & 130 & 414 \\
D & 80.0 & 253 & 478 \\
E & 18.7 & 77.3 & 333 \\
F & 20.0 & 46.7 & 393 \\
G & 18.7 & 85.3 & 477 \\
H & 58.7 & 50.7 & 387 \\
I &
\end{tabular}

${ }^{a}$ Number of IFU per milliliter $\left(\times 10^{4}\right)$ of infected yolk sac material (each value represents the mean of three cultures). 
phogranuloma strains studied gave inclusion counts of $10^{7}$ to $10^{8} \mathrm{IFU} / \mathrm{ml}$ of infected yolk sac material, with no consistent difference among the three types of cell cultures. It was not possible to make reproducible reliable dilutions of yolk sac material giving only 10 to 300 IFU/cover slip when studying the lymphogranuloma organisms, due to their high infectivity in the culture systems used.

Isolation of $C$. trachomatis from clinical specimens using IUdR- and cycloheximidetreated cells. Of the 194 clinical specimens studied, 21 were positive for $C$. trachomatis. In 19 instances chlamydiae were isolated in cycloheximide-treated cells, and 11 of the same specimens also showed growth in IUdR-treated cells. Those samples that were positive in only one of the culture systems showed fewer than 10 IFU/cover slip. Samples positive in both culture systems gave up to 100 times more inclusions in the cycloheximide-treated cell cultures than in the IUdR-treated cell cultures.

\section{DISCUSSION}

One important factor in attempting to culture chlamydiae is to provide suitable conditions for the adsorption of the organism to the cell membrane of the host cell, and another is to create a favorable intracellular environment for the parasitism of chlamydiae. Eucaryotic cells have a net negative surface charge (19). This should also hold true for chlamydial cells, since their cell wall is similar to that of gram-negative bacteria. Thus, repellent physicochemical forces probably exist between the organism and the eucaryotic cell membrane. High-speed centrifugation $(3,6,18)$, or the use of the polycation diethylaminoethyl-dextran $(11,14)$, acts to overcome these forces. Kuo et al. (10) showed that treatment of HeLa 229 cells with polycations enhanced the infectivity of TRIC organisms, whereas infectivity was reduced by treatment with polyanions. This demonstrates the importance of overcoming the physicochemical forces that may interfere with the adsorption of chlamydiae to host cells in in vitro cultures.

Treatment of the eucaryotic host cells with irradiation or cytostatic drugs, such as IUdR or cytochalasin B, may favor the intracellular parasitism of chlamydiae by inhibiting protein and nucleic acid synthesis in the host cell. Such treatment may make more nutrients and precursors available to the infecting Chlamydia organism. Cycloheximide is a selective inhibitor of eucaryotic protein and nucleic acid synthesis, but does not affect procaryotic metabolism (1, 2). A depression of the host cell metabolism would be advantageous for the intracellular Chlamydia parasite.
In a study on the competition between Chlamydia psittaci and $\mathrm{L}$ cells for the isoleucine pools in host cells, Hatch (8) suggested that cycloheximide could enhance the growth of chlamydiae. In a preliminary study, we showed the usefulness of cycloheximide treatment of McCoy cells for the isolation of $C$. trachomatis from clinical specimens (13). At about the same time, Richmond (12) also discussed the use of cycloheximide for this-purpose.

The titration experiments showed that the optimal number of IFU was achieved by using $2 \mu \mathrm{g}$ of cycloheximide per $\mathrm{ml}$. In our preliminary report (13) on the use of cycloheximide for the isolation of $C$. trachomatis, we reported $1 \mu \mathrm{g} / \mathrm{ml}$ to be the optimal concentration. However, the drug used in that study was from a different batch. It is apparently necessary to perform titration experiments for each new batch before use. The same was also found to be true for IUdR. The two IUdR substances used, i.e., Stoxil and Iduridin, came from different commercial sources.

In the comparative study on the "untreated" and the cycloheximide-treated cells, the untreated cells were used 1 day after seeding, whereas the IUdR-treated cells were infected after 3 days. Even when the untreated cells are in a replicating stage, the intracellular environment should be rich in nutrients for a parasite such as Chlamydia, since these are young cells and the cell density is low. This might explain the comparatively high number of IFU in the untreated cells for some immunotypes. It might also explain why untreated McCoy cells can be used to culture $C$. trachomatis, as shown by Hobson et al. (9) and Richmond (12). The use of freshly seeded cells treated with a substance inhibiting growth of eucaryotic cells, such as cycloheximide, would further favor the intracellular parasitism of chlamydiae.

In our experience, cycloheximide-treated McCoy cells proved more efficient than McCoy cells treated with IUdR for the isolation of $C$. trachomatis from clinical specimens. Compared with earlier isolation techniques, the cycloheximide method has the additional advantage of being time saving, since pretreatment of the cells is not necessary.

\section{ACKNOWLEDGMENT}

This work was supported by grants from the Swedish Medical Research Council (16X-4509).

\section{LITERATURE CITED}

1. Alexander, J. J. 1968. Separation of protein synthesis in meningopneumonitis agent from that in $L$ cells by differential susceptibility to cycloherimide. J. Bacteriol. 95:327-332.

2. Alexander, J. J. 1969. Effect on infection with the me- 
ningopneumonitis agent on deoxyribonucleic acid and protein synthesis by its L-cell host. J. Bacteriol. 97:653-657.

3. Darougar, S., S. Cubitt, and B. R. Jones. 1974. Effect of high-speed centrifugation on the sensitivity of irradiated McCoy cell culture for the isolation of Chlamydia. Br. J. Vener. Dis. 50:308-312.

4. Ennis, H. L. 1966. Synthesis of ribonucleic acid in L cells during inhibition of protein synthesis by cycloheximide. Mol. Pharmacol. 2:543-557.

5. Gordon, F. B., I. A. Harper, A. L. Quan, J. D. Treharne, R. St. C. Dwyer, and J. A. Garland. 1969. Detection of Chlamydia (Bedsonia) in certain infections of man. I. Laboratory procedures: comparison of yolk sac and cell culture for detection and isolation. J. Infect. Dis. 120:451-462.

6. Gordon, F. B., G. B. Magruder, A. L. Quan, and H. G. Arm. 1963. Cell cultures for detection of trachoma virus from experimental simian infections. Proc. Soc. Exp. Biol. Med. 112:236-242.

7. Gordon, F. B., and A. L. Quan. 1965. Isolation of the trachoma agent in cell culture. Proc. Soc. Exp. Biol. Med. 118:354-359.

8. Hatch, T. P. 1975. Competition between Chlamydia psittaci and $\mathrm{L}$ cells for host isoleucine pools: a limiting factor in chlamydial multiplication. Infect. Immun. 12:211-220.

9. Hobson, D., F. W. A. Johnson, E. Rees, and I. A. Tait. 1974. Simplified method for diagnosis of genital and ocular infections with chlamydia. Lancet ii:555-556.

10. Kuo, C-C., S-P. Wang, and J. T. Grayston. 1973. Effect of polycations, polyanions, and neuraminidase on the infectivity of trachoma-inclusion conjunctivitis and lymphogranuloma venereum organisms in HeLa cells: sialic acid residues as possible receptors for trachoma- inclusion conjunctivitis. Infect. Immun. 8:74-79.

11. Kuo, C-C., S-P. Wang, B. B. Wentworth, and J. T. Grayston. 1972. Primary isolation of TRIC organisms in HeLa 229 cells treated with DEAE-dextran. J. Infect. Dis. 125:665-668.

12. Richmond, S. J. 1976. Growth of Chlamydia trachomatis in cell culture. Lancet $\mathbf{i}: 865$.

13. Ripa, K. T., and P.-A. Märdh. 1977. New, simplified culture technique for Chlamydia trachomatis, p. 323-327. In D. Hobson and K. K. Holmes (ed.), Nongonococcal urethritis and related infections. American Society for Microbiology, Washington, D.C.

14. Rota, T. R., and R. L. Nichols. 1971. Infection of cell cultures by trachoma agent. Enhancement by DEAEdextran. J. Infect. Dis. 124:419-421.

15. Sisler, H. D., and M. R. Siegel. 1967. Cycloheximide and other glutarimide antibiotics, p. 283-307. In D. Gottlieb and P. D. Shaw (ed.), Antibiotics, vol. 1. Springer-Verlag, New York.

16. Sompolinsky, D., and S. Richmond. 1974. Growth of Chlamydia trachomatis in McCoy cells treated with cytochalasin B. Appl. Microbiol. 28:912-914.

17. Tang, F. F., H. L. Chang, Y. T. Huang, and K. C. Wang. 1957. Studies on the etiology of trachoma with special reference to isolation of the virus in chick embryo. Chin. Med. J. 75:429-447.

18. Weiss, E., and E. R. Dressler. 1960. Centrifugation of rickettsiae and viruses onto cells and its effect on infection. Proc. Soc. Exp. Biol. Med. 103:691-695.

19. Weiss, $L$. 1972. Interactions between normal and malignant cells, p. 377-447. In M. L. Hair (ed.), The chemistry of biosurfaces. Marcell Dekker Inc., New York.

20. Wentworth, B. B., and E. R. Alexander. 1974. Isolation of Chlamydia trachomatis by use of 5-iodo-2-deoxyuridine-treated cells. Appl. Microbiol. 27:912-916. 